\title{
Endoscopic treatment of duodenal perforation following laparoscopic cholecystectomy
}

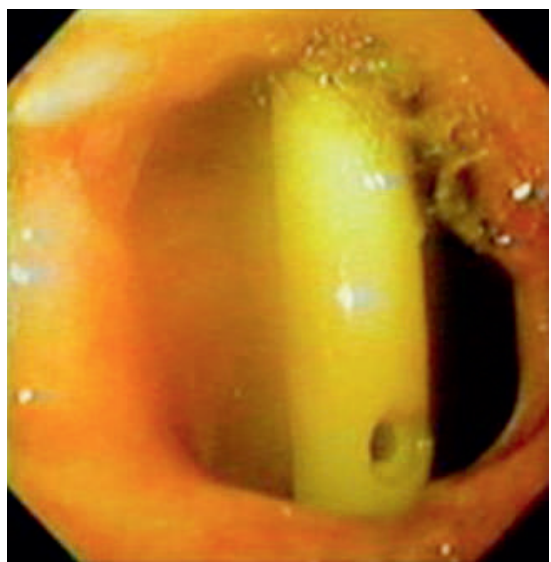

Fig. 1 Endoscopic view of the perforation with the drainage tube visible.

Duodenal perforation is an uncommon complication of laparoscopic cholecystectomy and is associated with significant morbidity and mortality when diagnosis is delayed [1-3]. Endoscopic closure has not been reported, although it has become an alternative for selected patients with postoperative gastrointestinal fistulas in other locations [4].

We report the case of a 59-year-old male who underwent endoscopic retrograde cholangiopancreatography (ERCP) and laparoscopic cholecystectomy for cholecystitis with choledocholithiasis. He developed pain and fever 2 days later. Ultrasonography showed subhepatic fluid collection so laparotomy was performed. Fluid collection on the gallbladder fossa was seen but no bile leakage was noticed. Subhepatic drainage was left in place, discharging up to $1200 \mathrm{~mL} /$ day. The patient was sent to our hospital 8 days later for assessment of the biliary tree. During ERCP a 12-mm perforation on the duodenal bulb was found. The previously placed drainage tube was visible through the perforation ( $\bullet$ Fig. 1 ). Access with a gastroscope to the abdominal cavity was gained through the perforation, which was limited to the right hypochondrium and blocked by the omentum ( $\bullet$ Video 1). Closure with endoclips was attempted but maximum opening of the endoclips did not embrace the edges of the perforation. Closure was then achieved with a Vicryl mesh plug fixed to the borders of the perforation with endoclips ( Video 2). A nasojejunal feeding probe and a nasogastric tube were left in place. Subhepatic drainage was not removed and intravenous antibiotics were administered.

Over the following 72 hours, drainage output reduced to zero. On day 7, a liquid diet was started and, following the removal of the subhepatic drainage, the patient was discharged.

Endoscopy_UCTN_Code_TTT_1AO_2AI

\section{Video 1}

Abdominal cavity exploration through duodenal perforation. Falciform ligament, diaphragmatic peritoneum, and the surface of the left liver lobe are seen.

\section{Video 2}

Vicryl plug placement.
J. Isaguirre, S. Gutiérrez, R. Ongay,

\section{R. Perez Ravier}

Department of Gastroenterology and Digestive Endoscopy, Hospital Italiano, Mendoza, Argentina

\section{References}

1 Peters JH, Gibbons GD, Innes JT et al. Complications of laparoscopic cholecystectomy. Surgery 1991; 110: 769- 777

2 Ress AM, Sarr MG, Nagorney DM et al. Spectrum and management of major complications of laparoscopic cholecystectomy. Am J Surg 1993; 165: 655-662

3 Kwon AH, Inui H, Kamiyama Y. Laparoscopic management of bile duct and bowel injury during laparoscopic cholecystectomy. World J Surg 2001; 25: 856 - 861

4 Truong S, Böhm G, Klinge $U$ et al. Results after endoscopic treatment of postoperative upper gastrointestinal fistulas and leaks using combined Vicryl plug and fibrin glue. Surg Endosc 2004; 18: 1105-1108

\section{Bibliography}

DOI $10.1055 / \mathrm{s}-2007-995731$

Endoscopy 2008; 40: E138

(c) Georg Thieme Verlag KG Stuttgart · New York . ISSN 0013-726X

Corresponding author

\section{S. Gutiérrez, MD}

Servicio de Gastroeterología y

Endoscopía Digestiva

Hospital Italiano de Mendoza

Av. Lateral Norte de Acceso Este 1070

CP 5519

Guaymallén

Mendoza

Argentina

Fax: +54-261-4324666

xebax@gutierrez.net.ar 